\title{
Effects of $n-3$ fatty acids on postprandial triacylglycerol and hormone concentrations in normal subjects
}

\author{
BY CHRISTINE M. WILLIAMS, F. MOORE, L. MORGAN AND J. WRIGHT \\ The Nutrition Research Group, Department of Biochemistry, University of Surrey, \\ Guildford $G U 25 \mathrm{XH}$
}

(Received 17 June 1991-Accepted 17 December 1991)

\begin{abstract}
The present study reports results from two investigations to determine effects of a 6-week period of moderate $n-3$ fatty acid supplementation $(2 \cdot 7 \mathrm{~g} / \mathrm{d})$ on fasting and on postprandial triacylglycerol and metabolic hormone concentrations in response to standard test meals. In the first study postprandial responses were followed for $\mathbf{2 1 0} \mathrm{min}$ after an early morning test meal challenge; in the second study responses to an evening test meal were followed during the evening and overnight for a total period of $12 \mathrm{~h}$. In both studies postprandial triacylglycerol responses to the test meals were significantly reduced after compared with before fish-oil supplementation. In the second study the triacylglycerol peak response seen between 200 and $400 \mathrm{~min}$ in subjects studied before supplementation with fish oils was almost completely absent in the same subjects after 6 weeks of $\boldsymbol{n - 3}$ fatty acid supplementation. Analysis of fasting concentrations of metabolites and hormones was carried out on the combined data from the two studies. There were no significant differences in total, low-density-lipoprotein- or high-densitylipoprotein-cholesterol concentrations during fish-oil supplementation, although there was considerable individual variation in cholesterol responses to the supplement. Concentrations of Apo-B and Apo-A1 were unchanged during supplementation with fish oils. Fasting and early morning postprandial GIP concentrations were lower in subjects taking fish oils, possibly due to acute effects of fish-oil capsules taken on the evening before the studies. In both studies fasting insulin and glucose and postprandial insulin concentrations remained unchanged following fish-oil supplementation. The results do not support the view that triacylglycerol-lowering effects of $\boldsymbol{n - 3}$ fatty acids are due to modulation of insulin secretion mediated via the enteroinsular axis. Further studies are required to determine the precise mechanism by which fish oils reduce both fasting and postprandial triacylglycerol concentrations.
\end{abstract}

Polyunsaturated fatty acids: Postprandial triacylglycerols: Metabolic hormones

A large number of studies have demonstrated lower fasting triacylglycerol concentrations in volunteers consuming fish-rich diets (von Lossonczy et al. 1978; Singer et al. 1985; Atkinson et al. 1987), and in subjects taking dietary supplements of fish oils (Sanders et al. 1981; Harris et al. 1983; Zucker et al. 1988). This effect has been attributed to the hypotriacyglycerolaemic properties of the $n-3$ fatty acids, eicosapentaenoic acid (EPA), and docosahexaenoic acid (DHA), found in high concentrations in oily fish and fish-oil supplements. Only two studies have investigated effects of increased $n-3$ fatty acid intake on postprandial triacylglycerol concentrations (Harris et al. 1988; Weintraub et al. 1988). Such a paucity of studies is surprising in view of the increasing recognition of the potential atherogenic properties of postprandial lipoproteins, particularly the chylomicron remnants (Zilversmit, 1979; Simons et al. 1987). In the present study we have investigated the effect of a dietary supplement of fish oils on postprandial triacylglycerol responses to standard test meals in subjects taking their usual diets. For ease of investigation most postprandial studies are conducted during the daytime, despite the fact that individuals eat the greater proportion of their daily nutrient intake in the evening, so that postprandial effects at this 
time are likely to be of greater relevance. For this reason we have included both daytime and overnight postprandial studies in our present investigations and have used normal foods rather than liquid meals as test meals, in order to simulate the usual physiological situation.

The hypotriacylglycerolaemic properties of $n-3$ fatty acids have largely been attributed to their inhibitory actions on hepatic very-low-density-lipoprotein (VLDL) synthesis and output (Harris, 1989), although the precise mechanisms are not clearly understood. Insulin is known to be the main regulatory hormone controlling hepatic VLDL production (Gibbons, 1990), but altered insulin response in subjects taking fish oils has not been reported. Secretion of the insulinotropic gut hormone GIP (glucose-mediated insulinotropic polypeptide), is known to be influenced by the type and amount of dietary fat (Morgan et al. 1988), and a recent study has shown that GIP response to a fish-oil-rich test meal is much less than to an equivalent saturated fat meal (Lardinois et al. 1988). Therefore, modulation of insulin secretion via the enteroinsular axis may provide a hormonal mechanism by which $n-3$ fatty acids could influence hepatic VLDL metabolism. In order to investigate this possibility as part of the present investigation, we have measured fasting and postprandial concentrations of the hormones insulin and GIP, in subjects before and during the period of fish-oil supplementation.

\section{SUBJECTS AND METHODS}

\section{Subjects}

Fourteen volunteer subjects (five male; nine female) were recruited from the staff and student population of the University of Surrey. Subjects were all healthy and satisfied the inclusion criteria for the studies which were: (1) body-weight $\pm 15 \%$ ideal body-weight and no recent weight change, (2) not following a therapeutic or specialized diet or taking dietary supplements of fatty acids, (3) fasting cholesterol and triacylglycerol values within the normal range, (4) alcohol consumption $<30$ units per week and vigorous exercise $<5 \mathrm{~h}$ per week, (5) female subjects not taking oral contraceptives or other hormone preparations.

Informed consent was obtained from each participant before the study. The study had been approved by the Ethics Committees of the University of Surrey and St Lukes Hospital, Guildford. Subjects taking part in study 1 (two male; six female) had a mean age of 23.0 (SD 1.1) years and a mean body mass index (weight/height ${ }^{2}$; BMI) of 22.7 (SD 2.71). In study 2 (three males; three females), the mean values for age and BMI were 21.3 (SD 0.9) and $22.4(\mathrm{SD} 1.74)$ respectively.

\section{Study protocols}

Two studies were designed to test the effects of a dietary supplement of fish oils on fasting and postprandial concentrations of triacylglycerols, insulin and GIP. In study 1 the response to a $4 \cdot 2 \mathrm{MJ}(1000 \mathrm{kcal}), 50 \mathrm{~g}$ fat test meal was measured before and 6 weeks after fish-oil supplementation. The meal was taken at 09.00 hours and postprandial blood samples were collected over a $3.5 \mathrm{~h}$ period. Results obtained from the present study led to the design of study 2 in which postprandial responses to a $4.2 \mathrm{MJ}(1000 \mathrm{kcal}), 50 \mathrm{~g}$ fat test meal were measured before and 6 weeks after fish-oil supplementation. The meal was taken at 18.00 hours and blood samples were collected overnight for a period of $12 \mathrm{~h}$.

\section{Fish-oil supplement}

In both studies each subject was required to take nine fish-oil capsules (British Cod Liver Oils Ltd (Hull)) daily for 6 weeks and were recommended to take three capsules three times daily with food. The dose of $n-3$ fatty acids provided by nine capsules was $2 \cdot 7 \mathrm{~g} / \mathrm{d}$. The capsules also provided $452 \mathrm{~kJ}$ (108 kcals) and $68 \mathrm{mg}$ cholesterol/d. The total fatty acid 
Table 1. Studies 1 and 2. Fatty acid composition $(\mathrm{g} / 100 \mathrm{~g})$ of fish-oil capsules administered

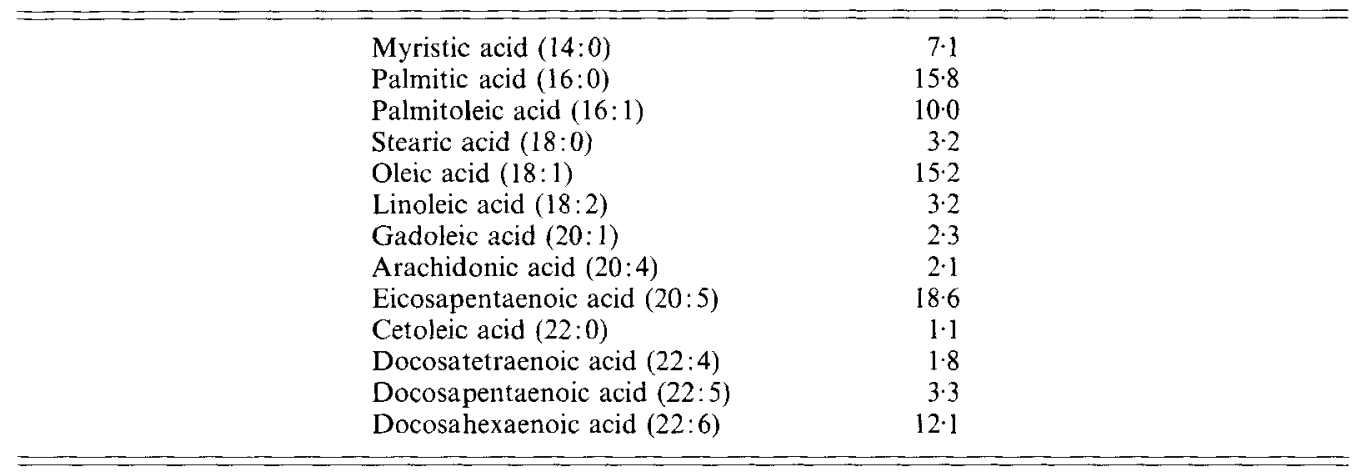

profile of the capsules is shown in Table 1. Compliance to the daily dose was ascertained by questioning the subjects at intervals and by the return of unused capsules at the end of the study.

\section{Study procedures}

In both studies subjects' responses to a test meal were investigated on two occasions, before and at the end of a 6-week period of fish-oil supplementation. Subjects were asked to complete a detailed dietary diary for $3 \mathrm{~d}$ in the week preceding each visit, and a $24 \mathrm{~h}$ dietary recall interview was conducted on each morning of the study. Subjects attended the study centre after an overnight fast and were asked to refrain from alcohol consumption on the evening before each visit.

Study 1. Effect of fish-oil supplementation on the early postprandial response

Eight subjects accepted for the study attended the study centre at 08.30 hours. Following insertion of an indwelling cannula into an antecubital vein two fasting blood samples were taken at 10 min intervals ( -10 and 0 min samples) and subjects asked to consume the test meal within $20 \mathrm{~min}$. Cannulas were kept patent by infusion of a small volume of sodium citrate after each sample had been collected. The content and nutrient composition of the morning test meal is shown in Table 2 . Blood samples were collected at 15 min intervals for the first hour and at $30 \mathrm{~min}$ intervals thereafter until $210 \mathrm{~min}$. Subjects were allowed a decaffeinated beverage drink without milk or sugar, at 150 min after the test meal, but were allowed no other food or drink during the study period.

Study 2. The effect of fish-oil supplementation on the long-term postprandial response Six subjects accepted for the study attended the study centre at 08.30 hours on the morning of the day of the study for the collection of a fasting baseline blood sample. The subjects were provided with a standard breakfast and packed lunch, to ensure that daytime nutrient intake was identical on both occasions. The lunch was eaten at approximately 13.00 hours on each occasion. Subjects were then allowed to go about their normal daily activities, but refrained from vigorous exercise. At 18.00 hours subjects returned to the study centre and following the insertion of an indwelling cannula and collection of a basal blood sample, were given a test meal dinner, the content and nutrient composition of which is shown in Table 2. Conditions of sample collection were the same as those for study 1. Subjects remained at the study centre throughout the evening and overnight. Blood samples were 
Table 2. Studies 1 and 2. Content and nutrient composition ( $\mathrm{g}$ ) of test meals administered to normal subjects

\begin{tabular}{|c|c|c|}
\hline & Study 1 & Study 2 \\
\hline Content (g) & $\begin{array}{l}\text { Bread } 105 \\
\text { Butter } 24 \\
\text { Cheddar cheese } 60 \\
\text { Cornflakes } 22 \\
\text { Sugar } 15 \\
\text { Whole milk } 300\end{array}$ & $\begin{array}{l}\text { Potatoes } 200 \\
\text { Butter } 10 \\
\text { Cheddar cheese } 70 \\
\text { Tinned peaches } 300 \\
\text { Double cream } 30 \\
\text { Whole milk } 300\end{array}$ \\
\hline $\begin{array}{l}\text { Nutrient } \\
\text { composition }\end{array}$ & & \\
\hline Energy: kJ & 4190 & 4199 \\
\hline kcals & 1002 & 1004 \\
\hline Protein & 36 & 33 \\
\hline Fat & 53 & 57 \\
\hline Carbohydrate & 101 & 96 \\
\hline
\end{tabular}

collected at $30 \mathrm{~min}$ intervals for the first $3 \mathrm{~h}$ and at hourly intervals thereafter. Subjects were allowed a decaffeinated beverage without milk or sugar at approximately 22.30 hours, but no other food or drink was permitted. Subjects slept normally throughout the night, the indwelling cannulas allowing blood samples to be collected with minimal disturbance to the volunteers.

In both studies blood samples collected at all time-periods were analysed to determine concentrations of triacylglycerols, insulin and GIP. Fasting blood samples were also analysed to determine concentrations of total, low-density-lipoprotein (LDL)- and highdensity-lipoprotein (HDL)-cholesterol, Apo-B, Apo-A1 and glucose. The methods employed for these analyses are outlined.

\section{Laboratory procedures}

Portions of each blood sample were placed into separate blood tubes for preparation of plasma and serum. Samples were centrifuged at $2500 \mathrm{rev} . / \mathrm{min}$ for $10 \mathrm{~min}$, plasma and serum separated and separate portions were stored immediately at $-20^{\circ}$ for analysis of triacylglycerols, insulin, GIP, glucose, Apo-B and Apo-A1. Plasma samples for HDLcholesterol analysis were first pretreated with magnesium chloride to precipitate the VLDLand LDL-cholesterol-containing lipoproteins and HDL-cholesterol was determined on the supernatant fraction. Total cholesterol was determined on untreated plasma and LDLcholesterol calculated using the Friedwald equation (Friedwald et al. 1972).

\section{Analytical precision}

All analytical procedures included the analysis of standards and internal quality control samples. Sample runs which included values for standards outside $5 \%$ of the known value, or a quality-control result outside of the quoted range, were repeated to minimize analytical variability. Samples for individual subjects obtained from the two days of investigation were analysed within the same run to minimize within-subject variability.

Triacylglycerols, glucose, cholesterol, Apo-B and Apo-AI

Analysis of plasma triacylglycerols, glucose and cholesterol were carried out using enzymic, spectrophotometric methods using the Cobas-Bio centrifugal analyser. Immunoturbidimetric methods were used to determine serum Apo-B and Apo-Al concentrations using 
the same instrument. Triacylglycerol concentrations were determined using the Triglyceride PAP Uni-kit (Roche Diagnostics Ltd), glucose using the Hexokinase Uni-kit III (Roche Diagnostics Ltd), cholesterol using the Cholesterol oxidase Uni-kit II (Roche Diagnostics Ltd). Apo-B concentrations were determined using Boehringer Mannheim CBR-Program antisera and standards.

\section{Insulin and GIP}

Plasma immunoreactive insulin was measured by a double-antibody radioimmunoassay technique using antisera supplied by Guildhay Antisera (Guildford, Surrey). Immunoreactive GIP was measured by a double-antibody radioimmunoassay technique using antisera raised against natural porcine GIP (Morgan et al. 1988).

\section{Statistical analysis of results}

For most data tabulated results are presented as mean values and standard deviations; individual time-points on graphs are presented as mean values with their standard errors to facilitate clarity of presentation. Logarithmic transformation of fasting and postprandial GIP values was carried out before statistical analysis of results to normalize data distribution. Therefore, results for fasting and postprandial GIP concentrations have been presented as their geometric means; standard errors for geometric means were too small to be shown in the figures.

Data for fasting concentrations of metabolites and hormones measured before and during fish-oil supplementation were combined for the two studies and statistical analysis carried out on the combined data. Comparisons of fasting metabolite and hormone concentrations and comparison of the peak increase in triacylglycerol concentrations, before and after fish-oil supplementation, were assessed for their significance using the Student's $t$ test for paired observations.

Comparisons of postprandial triacylglycerol, insulin and GIP concentrations before and after fish-oil supplementation, were carried out using a repeated measures design analysis of variance.

\section{RESULTS}

Calculation of the mean daily intakes of major nutrients, based on the combined data from the dietary diary and the $24 \mathrm{~h}$ recall, showed that no significant change in the intake of any of the major nutrients occurred during the period of fish-oil supplementation in either study (Table 3). None of the subjects showed any significant change in weight during the 6 weeks of supplementation.

Data for fasting concentrations of metabolites and hormones were combined for studies 1 and 2 and results presented as changes in concentration before and during fish-oil supplementation (Table 4). Fasting triacylglycerol concentrations were significantly reduced with fish-oil supplementation, from a mean value of 1.05 (SD 0.41$) \mathrm{mmol} / \mathrm{l}$ before, to 0.79 (SD 0.18$) \mathrm{mmol} / \mathrm{l}$ during supplementation $(P<0.001)$. Fasting GIP concentrations were also significantly lower during fish-oil supplementation; mean values were 204 (SD $5.92) \mathrm{pg} / \mathrm{ml}$ before, compared with 134 (SD 2.96) pg/ml during supplementation $(P<0 \cdot 01)$. Values for concentrations of other lipoproteins, apo-proteins, glucose and insulin were not significantly altered during fish-oil supplementation. Total cholesterol, LDL-cholesterol and apo-B responses to fish-oil supplementation were extremely variable, with eight of the fourteen subjects showing moderate increases in cholesterol and apo-B, four showing decreases and two showing constant cholesterol and apo-B concentrations. Differences in individual response were not related to sex or to differences in insulin or GIP response. Fig. 1 (study 1), shows postprandial responses to the standard test meal of triacylglycerols, 
Table 3. Studies 1 and 2. Daily intakes ( $\mathrm{g}$ ) of major nutrients of normal subjects (Values are means and standard deviations for no. of subjects shown)

\begin{tabular}{|c|c|c|c|c|}
\hline & \multicolumn{2}{|c|}{ Before supplementation } & \multicolumn{2}{|c|}{ During supplementation } \\
\hline & Mean & SD & Mean & SD \\
\hline \multicolumn{5}{|l|}{ Study $1(n 8)$} \\
\hline Energy: kJ & 8414 & 2860 & 8452 & 2258 \\
\hline kcals & 2012 & 684 & 2021 & 540 \\
\hline Fat & $80 \cdot 5$ & $14 \cdot 7$ & $92 \cdot 3$ & $13 \cdot 7$ \\
\hline Carbohydrate & 240 & $77 \cdot 8$ & 212 & $67 \cdot 4$ \\
\hline Protein & $69 \cdot 5$ & $19 \cdot 3$ & $64 \cdot 1$ & $14 \cdot 7$ \\
\hline \multicolumn{5}{|l|}{ Study $2(n 6)$} \\
\hline Energy: kJ & 8970 & 1133 & 8213 & 1572 \\
\hline keals & 2145 & 271 & 1964 & 376 \\
\hline Fat & 94.8 & $17 \cdot 6$ & $89 \cdot 2$ & $17 \cdot 5$ \\
\hline Carbohydrate & 249 & 42 & 221 & 45 \\
\hline Protein & $66 \cdot 7$ & $12 \cdot 4$ & $62 \cdot 4$ & $16 \cdot 2$ \\
\hline
\end{tabular}

Table 4. Studies 1 and 2. Combined values for change in fasting metabolite and hormone concentrations after 6 weeks of fish-oil supplementation for normal subjects $\dagger^{\dagger}$

(Values are means and standard deviations for fourteen subjects)

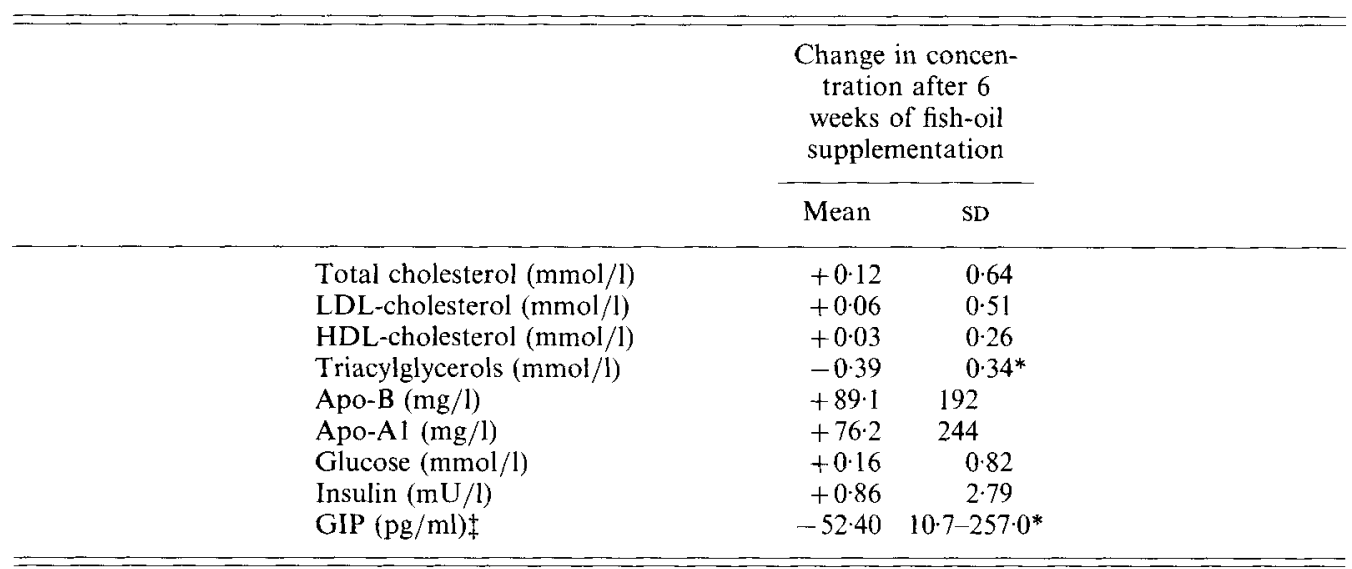

LDL, low-density-lipoprotein; HDL, high-density-lipoprotein; GIP, glucose-mediated insulinotropic polypeptide.

$* P<0.01$.

$\dagger$ For details of test meals and nutrient intakes, see Tables 1 and 2.

$\ddagger$ Presented as geometric mean with $95 \%$ confidence limits.

insulin and GIP. It can be seen that during fish-oil supplementation, postprandial triacylglycerol concentrations were lower at all time-points measured $(P<0.001)$. However, because triacylglycerol values did not reach a plateau during the time-course of the experiment it is not possible to calculate the peak response in order to determine whether these lower values are the result of lower fasting, baseline triacylglycerol values (which reflect endogenous VLDL output), or whether there is an additional effect due to increased rate of removal of exogenous triacylglycerol. 
(a)

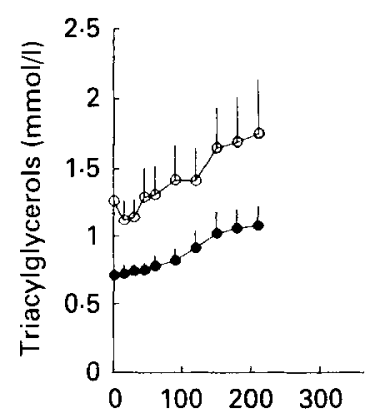

(b)

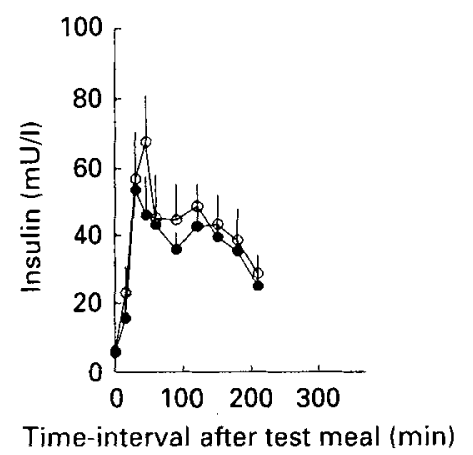

(c)

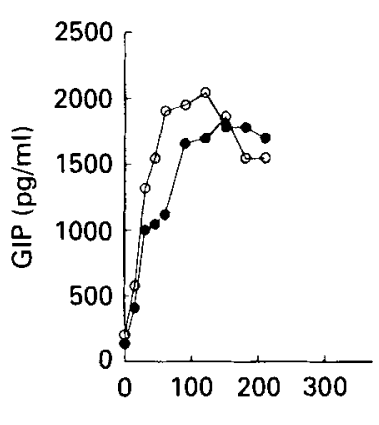

Fig. 1. Early morning postprandial triacylglycerol $(a)$, insulin $(b)$ and glucose-mediated insulinotropic polypeptide (GIP) (c) responses to a standard test meal before $(O)$ and 6 weeks after fish-oil supplementation $(0)$ in normal subjects. Triacylglycerol and insulin values are shown as their arithmetic means with their standard errors represented by vertical bars; GIP values are shown as their geometric means for eight subjects in all cases. For details of test meals and nutrient intakes, see Tables 1 and 2.

Postprandial GIP concentrations were significantly lower after fish-oil supplementation $(P<0.05)$, with the most marked difference evident in the early part of the postprandial response curve. There were no significant differences in postprandial insulin concentrations, measured before fish-oil supplementation, compared with those measured after supplementation.

Fig. 2 (study 2) shows postprandial concentrations of triacylglycerols, insulin and GIP before and after fish-oil supplementation. The postprandial triacylglycerol response to the test meal was lower in subjects taking fish-oil supplements $(P<0 \cdot 001)$. In particular there was a notable blunting of the postprandial triacylglycerol peak between 180 and 420 min compared with the response demonstrated by subjects before fish-oil supplementation. Fig. 3 shows the peak postprandial triacylglycerol response before and during fish-oil supplementation for subjects in study 2 . Before fish-oil supplementation the mean peak value for postprandial triacylglycerols at $240 \mathrm{~min}$ was 1.27 (SD 0.29) $\mathrm{mmol} / \mathrm{l}$, with a preprandial value of 0.94 (SD 0.24$) \mathrm{mmol} / \mathrm{l}$, a mean increase of 0.34 (SD 0.19) $\mathrm{mmol} / \mathrm{l}(P<$ $0.01)$. During fish-oil supplementation the postprandial triacylglycerol value at $240 \mathrm{~min}$ was 0.85 (SD 0.16) $\mathrm{mmol} / 1$, with a preprandial value of 0.71 (SD 0.30$) \mathrm{mmol} / \mathrm{l}$, a mean increase of 0.19 (SD 0.25$) \mathrm{mmol} / 1$ (not significant). These findings support the view that removal of exogenous triacylglycerols is enhanced following fish-oil supplementation.

Postprandial concentrations of insulin and GIP were not significantly different after fishoil supplementation in study 2 .

\section{DISCUSSION}

Both studies have clearly shown that dietary supplementation with fish oils results in significant reductions in fasting and postprandial triacylglycerol concentrations. Other studies have investigated postprandial responses to meals administered during the early morning, so that effects of fish oils on the triacylglycerol response to test meals administered in the evening, a time at which most individuals consume the greater proportion of their total daily food intake, have not been studied. The results of the present study suggest that the triacylglycerol-lowering effects of fish oils are similar at both times of day since blunted triacylglycerol responses to standard test meals containing $50 \mathrm{~g}$ fat were observed following both morning and evening test meal studies. The pattern of triacylglycerol response to the test meals differed between the two studies, both before and 
(a)

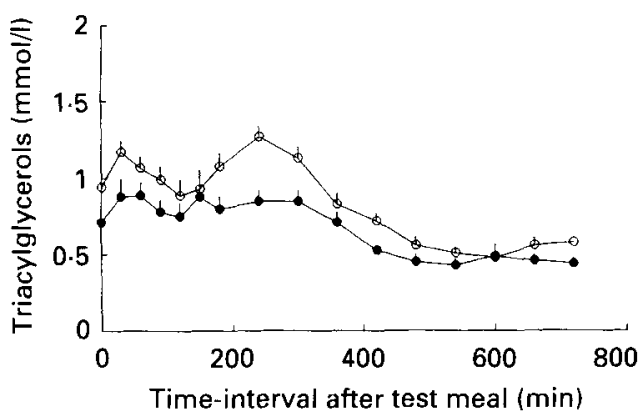

(b)

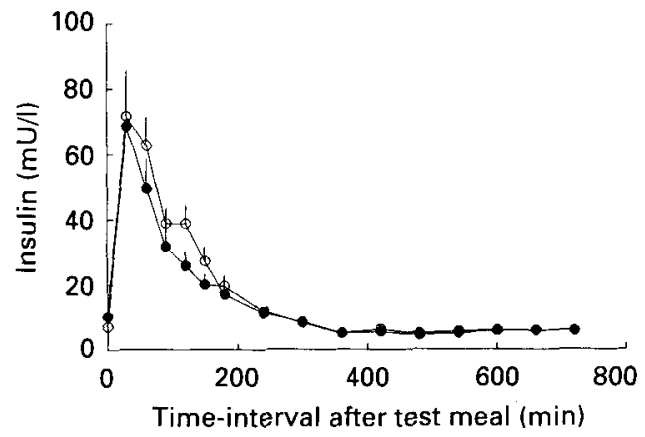

(c)

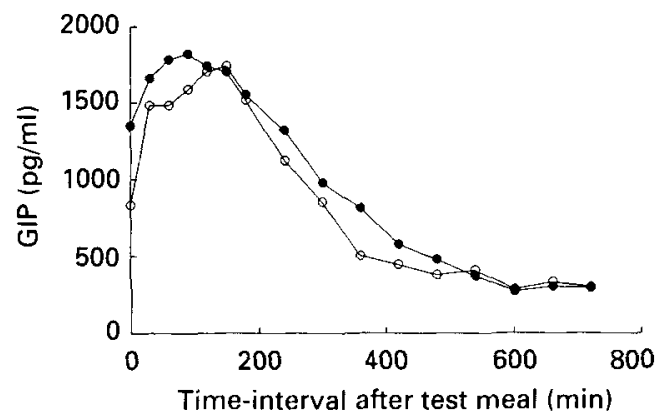

Fig. 2. Evening and overnight postprandial triacylglycerol $(a)$, insulin $(b)$ and glucose-mediated insulinotropic polypeptide (GIP) $(c)$, responses to a standard test meal before $(O)$ and 6 weeks after fish-oil supplementation $(\boldsymbol{O})$ in normal subjects. Triacylglycerol and insulin values are shown as their arithmetic means with their standard errors represented by vertical bars; GIP values are shown as their geometric means, for six subjects in all cases. For details of test meals and nutrient intakes, see Tables 1 and 2.

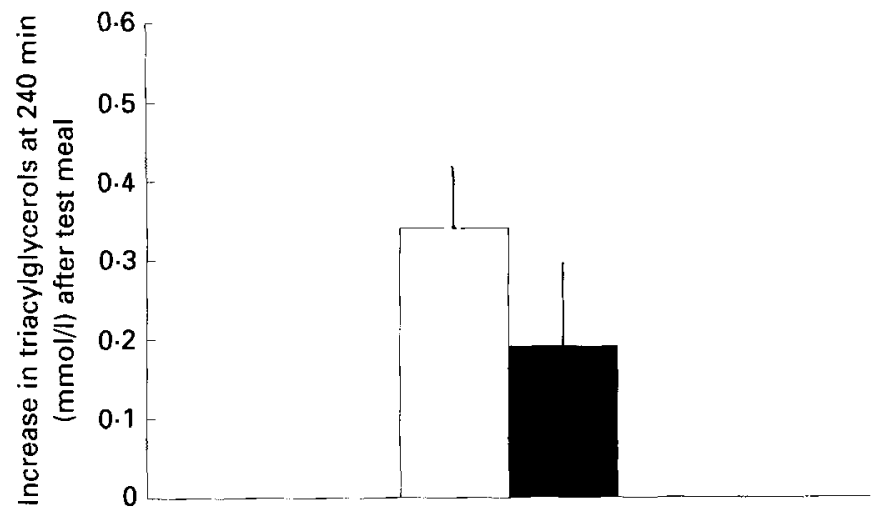

Fig. 3. Postprandial triacylglycerol response at $240 \mathrm{~min}$ after a standard test meal in normal subjects before ( $\square$ ), and 6 weeks after fish-oil supplementation $(\mathbf{U})$. Values are means with their standard errors represented by vertical bars for six subjects. For details of test meals and nutrient intakes, see Tables 1 and 2 . 
during fish-oil supplementation. In the early morning study (study 1), subjects were investigated after an overnight fast and a steady, continuous increase in triacylglycerol concentration was observed in response to the test meal (which was less marked during fishoil supplementation). Sampling was only continued up to $210 \mathrm{~min}$ in the present study and triacylglycerol values had not reached a plateau at the end of sampling. In the evening and overnight study (study 2) the test meal was administered at approximately 18.00 hours. Subjects had consumed a standard packed lunch at 13.00 hours, so that at the time of the test meal these subjects would have been in the late postprandial state from lunch. In this second study a small increase in triacylglycerol concentrations from the preprandial level was observed in the first hour after the test meal, with a second, more marked increase between 180 and $360 \mathrm{~min}$ (both peaks were reduced during fish-oil supplementation). Although different foods were used as part of the test meals in the two studies, the nutrient compositions of the two meals were very similar and the meals were also similar in their mixture of solid and liquid foods. It, therefore, seems unlikely that the different pattern of triacylglycerol response in the evening compared with the morning study reflects differences in the nature of the test meals. A more likely explanation is that the 'early peak' seen in study 2, represents the late part of the lunch-time postprandial triacylglycerol response. However Cohn et al. (1988), have shown that many subjects show biphasic or multiple triacylglycerol peaks after fat meals and this appears to be an individual response. Although reasons for the appearance of these peaks are not known, they must reflect differences in stomach emptying or hormonal responses to meal feeding, or both. None of our subjects showed multiple peaks in the early morning study, but all subjects in the evening study showed two triacylglycerol 'peaks'. The possibility that subjects are more likely to show biphasic or multiple triacylglycerol postprandial peaks to foods administered in the evening, due to diurnal variations in digestion, absorption and disposition of foods must, therefore, also be considered as a possible explanation for the different pattern of triacylglycerol response observed in study 2 .

Although different triacylglycerol responses were seen in the morning compared with the evening studies, the results obtained clearly demonstrate the ability of fish-oil supplements to prevent marked increases in postprandial triacylglycerols throughout the day, so that over a $24 \mathrm{~h}$ period subjects consuming fish oils are likely to show less extreme fluctuations in circulating triacylglycerol concentrations. The potential health benefits of reductions in triacylglycerol levels have not been emphasized and this seems to be because, unlike cholesterol, elevated triacylglycerol concentrations are not normally considered to be a risk factor for coronary heart disease (CHD). This is despite the fact that the Framingham Heart Study showed that $90 \%$ of hypertriacylglycerolaemic men are at increased risk for CHD (Castelli, 1986). The Stockholm prospective study also found that in both sexes triacylglycerol levels are predictors of CHD (Carlson et al. 1979), and in post-menopausal women it has been recognized for some time that triacylglycerol levels are independently correlated with CHD risk (Reardon et al. 1985). In the present study the observation of marked reductions in postprandial triacylglycerols is of particular importance in the light of increasing evidence for the potential atherogenic properties of postprandial lipoproteins (Zilversmit, 1979; Stender \& Zilversmit, 1982; Kane et al. 1983). There is an emerging view that dietary changes which can result in enhanced rates of removal of triacylglycerolcontaining particles, and in particular the remnant lipoproteins, may be beneficial.

The hypotriacylglycerolaemic effects of fish oils are most likely due to the particular properties of the $n-3$ fatty acids, EPA and DHA, present in high concentrations in these oils. Previous studies which have investigated postprandial triacylglycerol-lowering effects of $n-3$ fatty acids have compared responses with standard test meals in subjects consuming background diets containing foods rich in fish oils with responses when subjects are 
consuming diets containing largely saturated fatty acids (Harris et al. 1988; Weintraub et al. 1988). These studies, like our own, demonstrated blunted postprandial triacylglycerol responses to a saturated fat meal in subjects taking a fish-oil-rich diet. However, the design of these crossover studies did necessitate changes in subjects' diets other than increased intake of fish-oil fatty acids. Most notably there was a significant reduction in saturated fatty acids so that, as discussed by Harris (1989), some of the reported effects could have been due to removal of these fatty acids rather than to the addition of the fish oils. The daily intakes of $n-3$ fatty acids in these studies were approximately $7 \mathrm{~g}$ (Weintraub et al. 1988), and $26 \mathrm{~g}$ (Harris et al. 1988). In the present study we have observed similar hypotriacylglycerolaemic effects in subjects consuming a more moderate daily intake of $2.7 \mathrm{~g}$ $n-3$ fatty acids in the form of a dietary supplement. Because there were no changes in the intake of other nutrients in subjects in our study, it may be concluded that the effects observed are due to the particular properties of the $n-3$ fatty acids rather than to dietary adjustments made in order to achieve increased EPA and DHA intake.

Although the triacylglycerol-lowering effects of fish oils have been well documented, effects of these oils on the other lipoproteins have been less clearly established. In the present study we found no significant effect of fish-oil supplementation on fasting total and LDL-cholesterol concentrations or on apo-B concentrations. However, there was considerable individual variation in cholesterol response to fish oils; eight subjects showed increased cholesterol, four showed decreased cholesterol and two showed no change in cholesterol concentration during fish-oil supplementation. Harris (1989), in a review of forty-one studies conducted on effects of fish oils on lipid metabolism in normal subjects, showed that fourteen reported increased LDL concentrations, twenty found decreased concentrations, and in the remainder there was no change. Reasons for the wide variability in cholesterol response to $n-3$ supplementation are not known, but the possibility that fish oils may increase cholesterol concentrations in some individuals needs to be taken into account in assessing the health benefits of dietary $n-3$ fatty acids. The mechanisms by which dietary fish oils reduce fasting triacylglycerol concentrations, and also result in blunted triacylglycerol responses to a saturated fat meal, require further investigation. Our present knowledge is inadequate and is mostly derived from in vivo and in vitro studies in animals. These studies and the study of Nestel et al. (1984), in human volunteers, support the view that lower fasting triacylglycerol levels in response to fish oils reflect reductions in hepatic VLDL output. Animal studies have shown that $n-3$ fatty acids inhibit hepatic triacylglycerol synthesis, probably via inhibition of 1,2-diacylglycerol transferase (EC 2.3.1.20) (Rustan et al. 1988), and enhance ketone production through induction of peroxisomal oxidation (Bergseth et al. 1986). Although insulin is an important regulator of these pathways in man and animals (Gibbons, 1990), our studies suggest these effects are unlikely to be secondary to reductions in insulin secretion since identical insulin responses were observed before and during the period of fish-oil supplementation in both studies. It would, therefore, appear that reduced VLDL output reflects direct inhibition of hepatic lipogenesis and apoprotein synthesis by $n-3$ fatty acids, effects which have been observed in HepG 2 cells incubated with EPA (Wong \& Nestel, 1987). Whether the blunted lipidaemic response to a fat meal observed in the present study can also be attributed to the reduction in VLDL output is not clear. In the study of Weintraub et al. (1988) the peak increase in triacylglycerol concentration was found to correlate positively with fasting triacylglycerol values. Since clearance of both exogenous chylomicron triacylglycerols and endogenous VLDL triacylglycerols is achieved via a common pathway involving the enzyme lipoprotein lipase (EC 3.1.1.34; LPL), this observation lends support to the view that enhanced removal of exogenous triacylglycerols is due to reduced competition for the common removal mechanism secondary to the lower fasting triacylglycerol levels. However, in the present 
study we found no correlation between fasting triacylglycerol values and the peak triacylglycerol response. Harris (1989) has pointed out that in order for this mechanism to explain reduced postprandial lipidaemia, it would have to be assumed that LPL was saturated at pre-fish-oil-fasting triacylglycerol values, and became less saturated at the moderately lower values obtained on the fish-oil diet. This seems unlikely since in vivo studies in man suggest that LPL does not become saturated until levels greater than $5 \mathrm{mmol} / 1$ are reached (Brunzell et al. 1973), and none of the subjects in the present study had values approaching this level. Other mechanisms proposed to explain enhanced chylomicron removal rates following $n-3$ supplementation include: increased activity of the membrane-bound enzyme LPL, increased hydrolysis of $n$-3-containing chylomicrons, and reduced rates of chylomicron synthesis in intestinal enterocytes. Increased activity of LPL is a likely proposition since marked changes in membrane phospholipid-fatty acid composition and membrane function are observed in a wide range of human cells following $n-3$ supplementation. However, post-heparin LPL activity is not altered in subjects taking fish oils (Singer et al. 1983; Harris et al. 1988), and reduced activity of adipose tissue LPL has been reported in fish-oil-fed rats (Herzberg \& Rogerson, 1988). Studies of human adipose tissue LPL activity following fish-oil feeding are needed since it is unclear whether post-heparin LPL activity reflects activity of the enzyme in situ, an important consideration when membrane-mediated mechanisms may be responsible for effects of $n-3$ fatty acids. In both the present studies we observed lower fasting, early morning GIP concentrations in subjects taking fish oils, and in study 1 , in which postprandial measurements were conducted after an early morning test meal, the initial part of the GIP response curve was lower in subjects taking fish oils. GIP responses in the late postprandial phase of study 1 and all postprandial GIP responses measured in study 2 , in which postprandial samples were collected during the evening and overnight, were unaffected by fish-oil supplementation. These findings suggest that the blunted GIP responses may be due to residual effects of fish-oil capsules taken in the evening before each study day, and may reflect direct effects of fish oils on stomach emptying or basal GIP secretions. The effect is a moderate one and is clearly insufficient to result in changes in insulin secretion in response to the test meals.

\section{REFERENCES}

Atkinson, P. M., Wheeler, M. C., Mendelson, D., Piennar, N. \& Chetty, N. (1987). Effects of a 4-week, freshwater fish (trout) diet on platelet aggregation, platelet fatty acids, serum lipids and coagulation factors. American Journal of Hematology 24, 143-149.

Bergseth, S., Christiansen, E. N. \& Bremer, J. (1986). The effect of feeding fish oils, vegetable oils and clofibrate on the ketogenesis from long chain fatty acids in hepatocytes. Lipids 21, 508-514.

Brunzell, J., Hazzard, W. R., Porte, D. \& Bierman, E. L. (1973). Evidence for a common, saturable triglyceride removal mechanism for chylomicrons and very low density lipoproteins in man. Journal of Clinical Investigation 52, 1578-1585.

Carlson, L. A., Bottiger, L. E. \& Ahfeldt, P.-E. (1979). Risk factors for myocardial infarction in the Stockholm Prospective Study. Acta Medica Scandinavica 206, 351-360.

Castelli, W. P. (1986). The triglyceride issue: a view from Framingham. American Heart Journal 112, $432-437$.

Cohn, J.S., McNamara, J. R., Cohn, S. D., Ordovas, J. M. \& Schaefer, E. J. (1988). Postprandial plasma lipoprotein changes in subjects of different ages. Journal of Lipid Research 29, 469-479.

Friedwald, W. T., Levy, R. I. \& Frederickson, D. S. (1972). Estimation of the concentration of low density lipoprotein cholesterol in plasma without the use of the preparative ultracentrifuge. Clinical Chemistry 18 , 499-502.

Gibbons, G. F. (1990). Assembly and secretion of very-low-density lipoprotein. Biochemical Journal $268,1-13$.

Harris, W. S. (1989). Fish oils and plasma lipid and lipoprotein metabolism in humans: a critical review. Journal of Lipid Research 30, 785-807.

Harris, W. S., Connor, W. E., Alam, N. \& Illingworth, D. R. (1988). Reduction of postprandial triglyceridemia in humans by dietary $n-3$ fatty acids. Journal of Lipid Research 29, 1451-1460.

Harris, W. S., Connor, W. E. \& McMurry, M. P. (1983). The comparative reductions of the plasma lipids and lipoproteins by dietary polyunsaturated fats: salmon oil versus vegetable oils. Metabolism 32, 179-184. 
Herzberg, G. R. \& Rogerson, M. (1988). LPL activity in muscle and adipose tissue of rats fed glucose or fructose based diets containing fish oil. FASEB Journal 2, 852A.

Kane, J. P., Chen, G. C., Hamilton, R. L., Hardman, D. A., Malloy, M. J. \& Havel, R. J. (1983). Remnants of lipoproteins of intestinal and hepatic origin in familial dysbetalipoproteinemia. Arteriosclerosis 3, 47-56.

Lardinois, C. K., Starich, G. H. \& Mazzaferri, E. (1988). The postprandial response of gastric inhibitory polypeptide to various dietary fats in man. Journal of the American College of Nutrition 7, 241-247.

Morgan, L. M., Hampton, S. M., Tredger, J. A., Cramb, R. \& Marks, V. (1988). Modifications of gastric inhibitory polypeptide (GIP) secretion in man by a high-fat diet. British Journal of Nutrition 59, 373-380.

Nestel, P. J., Connor, W. E., Reardon, M. R., Connor, S., Wong, S. \& Boston, R. (1984). Suppression by diets rich in fish oil of very low density lipoprotein production in man. Journal of Clinical Investigation 74, 72-89.

Reardon, M. F., Nestel, P. J., Craig, I. H. \& Harper, R. W. (1985). Lipoprotein predictors of the severity of coronary artery disease in men and women. Circulation 71, 881-888.

Rustan, A. C., Nossen, J. O., Christiansen, E. N. \& Drevon, C. A. (1988). EPA reduces hepatic production and secretion of triacylglycerol by decreasing the activity of acyl-coenzyme A: 1,2-diacylglycerolacyltransferase. Journal of Lipid Research 29, 1417-1426.

Sanders, T. A. B., Vickers, M. \& Haines, A. P. (1981). Effect on blood lipids and haemostasis of a supplement of cod liver oil, rich in EPA and DHA, in healthy young men. Clinical Science 61, 317-324.

Simons, L. A., Dwyer, T., Simons, J., Bermann, J., Branson, J. \& Morgan, J. (1987). Chylomicrons and chylomicron remnants in coronary artery disease: a control study. Atherosclerosis 65, 181-189.

Singer, P., Jaeger, W., Wirth, M., Voigt, S., Naumann, E., Zimontkowski, S., Hadju, S. \& Godicke, W. (1983). Lipid and blood pressure-lowering effect of mackerel diet in man. Atherosclerosis 49, 99-108.

Singer, P., Wirth, H., Voigt, S., Richter-Heinrich, E., Godicke, E., Berger, I., Naumann, E., Listing, J., Hartrodt, W. \& Taube, C. (1985). Blood pressure- and lipid-lowering effect of mackerel and herring diets in patients with mild essential hypertension. Atherosclerosis 56, 223-235.

Stender, S. \& Zilversmit, D. B. (1981). Comparison of cholesterol ester transfer from chylomicrons and other plasma lipoproteins to aorta intima-media of cholesterol-fed rabbit. Arteriosclerosis 2, 493-499.

von Lossonczy, T. O., Ruiter, D. A., Bronsgeest-Schoute, H. C., van Gent, C. M. \& Hermuss, R. J. J. (1978). The effect of a fish diet on serum lipids in healthy human subjects. American Journal of Clinical Nutrition 31, $1340-1346$.

Weintraub, M. S., Zechner, R., Brown, A., Eisenberg, S. \& Breslow, J. L. (1988). Dietary polyunsaturated fats of the W-6 and W-3 series reduce postprandial lipoprotein levels. Journal of Clinical Investigation 82, $1884-1893$.

Wong, S. \& Nestel, P. S. (1987). Eicosapentaenoic acid inhibits the secretion of triacylglycerol and of apoprotein $B$ and the binding of LDL in HepG2 cells. Atherosclerosis 64, 139-146.

Zilversmit, D. B. (1979). Atherogenesis: a postprandial phenomenon. Circulation 60, 473-485.

Zucker, M. L., Bilyeu, D., Helmkamp, D. H., Harris, W. S. \& Dujovne, C. A. (1988). Effects of dietary fish oil on platelet function and plasma lipids in hyperlipoproteinemic and normal subjects. Atherosclerosis $73,13-22$. 